\title{
Analysis of Interacted Polyvanadate Based on its Preparation and Characterization
}

\author{
SUBRATA CHATTERJEE ${ }^{1 *}$ and P.P. JHA ${ }^{1}$, R.R. JHA ${ }^{2}$ and RAJESH KUMAR ${ }^{2}$ \\ ${ }^{1}$ Department of Chemistry, Ranchi College, Ranchi-834008, India \\ ${ }^{2}$ P.G. Department of Chemistry, R.U., Ranchi-834008, India \\ subrata.ch88@yahoo.com
}

Received 10 March 2014 / Revised 14 May 2014 / Accepted 26 May 2014

\begin{abstract}
A new triheteropoly complex was synthesized containing two hetero cations $\mathrm{Ni}^{2+}$ and $\mathrm{Co}^{2+}$. The polyvanadate anion has composition $\left[\mathrm{V}_{6} \mathrm{O}_{19}\right]$ maintaining $\mathrm{pH}$ at 4.5 . Product obtained was brown in appearance. The IR spectral analysis of the product suggests the presence of Ni-O, Co-O, $\mathrm{V}-\mathrm{O} \mathrm{V}=\mathrm{O}$ and $\mathrm{V}-\mathrm{O}-\mathrm{V}$ along with hydrogen bonded $\mathrm{H}_{2} 0$ group in the complex. The molecular weight of the triheteropoly complex is determined by cryscopic method in accordance with the calculated value. After the study of the thermal stability of the product. It was observed that the product had multistep decomposition as per TGA graph producing about $43.269 \%$ weight loss which was also duly supported by DTA graph indicating large exothermic peak maxima at $95.59^{\circ} \mathrm{C}$. On the basis of analytical, IR spectral and thermal stability data the composition of the product is assigned as $\mathrm{Na}_{4}$ $\left[\mathrm{Ni} \mathrm{CoV}_{6} \mathrm{O}_{19}\right] 22.5 \mathrm{H}_{2} \mathrm{O}$.
\end{abstract}

Keyword: Triheteropolyvanadate Preparation, Cryoscopy, IR Spectral Analysis, Thermal Analysis, DTA and TGA`

\section{Introduction}

Isopoly and heteropoly complexes were categorized as isopoly and heteropoly oxometalates by Michael T. Pope ${ }^{1-2}$. The synthesis is based on condensation process .The thermal stability increases because of occupation of hetero cation into the voids in the centre of vanadate anion $^{3-5}$ which leads to the formation of oxobridges by eliminations of water molecules. Such condensation reactions generally take place freely and reversibly in acidic medium. The condensation behavior of molybdates and vanadates is basically almost similar. The heteropoly complex is named according to IUPAC system ${ }^{6}$. In general the heteropoly complexes have been prepared by mixing the theoretical quantity of the required reactants in proper acidic medium followed by heating and crystallization. The DTA and TGA thermal study of the synthesized triheteropoly complex is important for the analysis of their thermal stability because the product isolated is associated with large number of water molecules. The thermal studies also help to fix the position of water molecules which may be between the interstices or at the peripheral of the crystals. 
The thermal stability of the complex is determined by dehydration method which chiefly involved differential thermal analysis and thermogravimetric analysis ${ }^{7,8}$ of the prepared complex compound may it also be either determined by direct heat treatment ${ }^{9-14}$ or by isothermal measurement. The characterization of the isolated triheteropolymolybdate containing two hetero atoms $\mathrm{Ni}^{2+}$ and $\mathrm{Co}^{2+}$ is based on elemental analysis, cryoscopic measurement, IR spectral studies and thermal analysis. Which include TGA and DTA studies of the product obtained. The molecular weight of the observed triheteropoly complex $\mathrm{Na}_{4}\left[\mathrm{Ni} \mathrm{CoV} \mathrm{O}_{19}\right] 22.5 \mathrm{H}_{2} \mathrm{O}$ is 1223 .

\section{Experimental}

$\mathrm{Na}_{4}\left[\mathrm{Ni} \mathrm{CoV} \mathrm{O}_{19}\right] 22.5 \mathrm{H}_{2} \mathrm{O}$ was freshly prepared. All other reagents used were of A.R. grade. The solutions were prepared in distilled water. The metals were estimated using an A.R. L3410 (Switzerland) atomic emission photometer and C, H and N by Coleman analyzer. The IR spectra $(\mathrm{KBr})$ were recorded on a Perkin-Elmer 577 spectrophotometry DTA and TGA experiment were carried out on a STA 409 (West Germany) analyzer.

\section{Molecular weight determination}

The molecular weight of the heteropoly complex was successfully determined by the method used by Alexander ${ }^{14}$ for the molecular weight determinations of certain inorganic polyacids and polyphosphates etc. in water and molten sodium sulphate decahydrate. The determination showed to be 1223 which is in the range of fair agreement.

\section{Preparation}

Preparation of the triheteropoly molybdates complex involves the mixing of ammonium molybdate, nickel carbonate and cobalt carbonate in the ratio 6:1:1 in aqucous solution separately with $10 \mathrm{~mL}$ of glacial acetic acid. The $\mathrm{pH}$ of the mixture was further adjusted to $4.5 \mathrm{pH}$ by adding about $5 \mathrm{~mL}$ of glacial acetic acid. Now the solution mixed together was refluxed for two hours and thirty minutes. It was cooled and left for crystallization. After three days, a brown coloured solid residue was obtained.

\section{Elemental analysis}

Elemental analysis was performed on the basis of prescribed method ${ }^{15}$ as per the percentage composition of the synthesized triheteropolymolybdate (Table 1). The proposal of composition of the complex may be given as 6:1:1. The apparent molecular weight of the prepared triheteropoly molybdate complex determined by cryscopic method was found to be $\mathrm{Na}_{4}\left[\mathrm{NiCoV}_{6} \mathrm{O}_{19}\right] 22.5 \mathrm{H}_{2} \mathrm{O}$ to be 1223 . It's observed molecular weight was 1221 .

Table 1. Elemental Analysis of $\mathrm{Na}_{4}\left[\mathrm{NiCoV}_{6} \mathrm{O}_{19}\right] 22.5 \mathrm{H}_{2} \mathrm{O}$

\begin{tabular}{lccccc}
\hline \multirow{2}{*}{ Elements } & \multicolumn{3}{c}{ Percentage found } & \multirow{2}{*}{ Mean } & $\begin{array}{c}\text { Percentage } \\
\text { Calculated }\end{array}$ \\
\cline { 2 - 4 } & Exp-1 & Exp-2 & Exp-3 & & 7.82 \\
Sodium & 7.56 & 7.83 & 7.81 & 7.52 \\
Nickel & 4.81 & 4.85 & 4.86 & 4.84 & 4.74 \\
Cobalt & 4.84 & 4.85 & 4.87 & 4.86 & 4.74 \\
Vanadium & 26.01 & 26.01 & 26.03 & 26.01 & 25.02 \\
Hydrogen & 3.64 & 3.84 & 3.86 & 3.85 & 3.67 \\
Oxygen & & & & 52.62 & 54.29 \\
By Difference & & & & & \\
\hline
\end{tabular}




\section{Results and Discussion}

IR spectral result of polyvanadate products

Infrared spectra of the above mentioned heteropoly compounds in $\mathrm{KBr}$ pellets have been recorded from $3392 \mathrm{~cm}^{-1}$ to $430.13 \mathrm{~cm}^{-1}$ on IR spectrophotometer as shown in (Figure 1). Perkin-Elmer Model 577 the peaks at $3392 \mathrm{~cm}^{-1}$ correspond to those of water. The peaks at $2131.34 \mathrm{~cm}^{-1}$ assigned as $\mathrm{H}_{2} \mathrm{O}$. The peaks at $1570.06 \mathrm{~cm}^{-1}$ can be attributed to $\delta\left(\mathrm{H}_{2} \mathrm{O}\right)$. The sharp peaks at $1570.06 \mathrm{~cm}^{-1}$ to $1344.38 \mathrm{~cm}^{-1}$ may be attributed to the presence of $\mathrm{H}_{2} \mathrm{O}$. The peaks at $1051.20 \mathrm{~cm}^{-1}$ is assigned as $(\mathrm{V}=\mathrm{O})$. The peaks at $967.33 \mathrm{~cm}^{-1}$ to $803.25 \mathrm{~cm}^{-1}$ are assigned as $\mathrm{V}-\mathrm{O}$. The peaks at $744.52 \mathrm{~cm}^{-1}$ and $535.21 \mathrm{~cm}^{-1}$ is assigned as $\mathrm{V}-\mathrm{O}-\mathrm{V}$. The peaks at $661.59 \mathrm{~cm}^{-1}$ is for Ni-O and the peaks at $431.34 \mathrm{~cm}^{-1}$ and $430.13 \mathrm{~cm}^{-1}$ is assigned for CoO. The theoretical values of some of the different stretching frequency to determine the force constant are also taken into consideration for assigning proper group frequency.

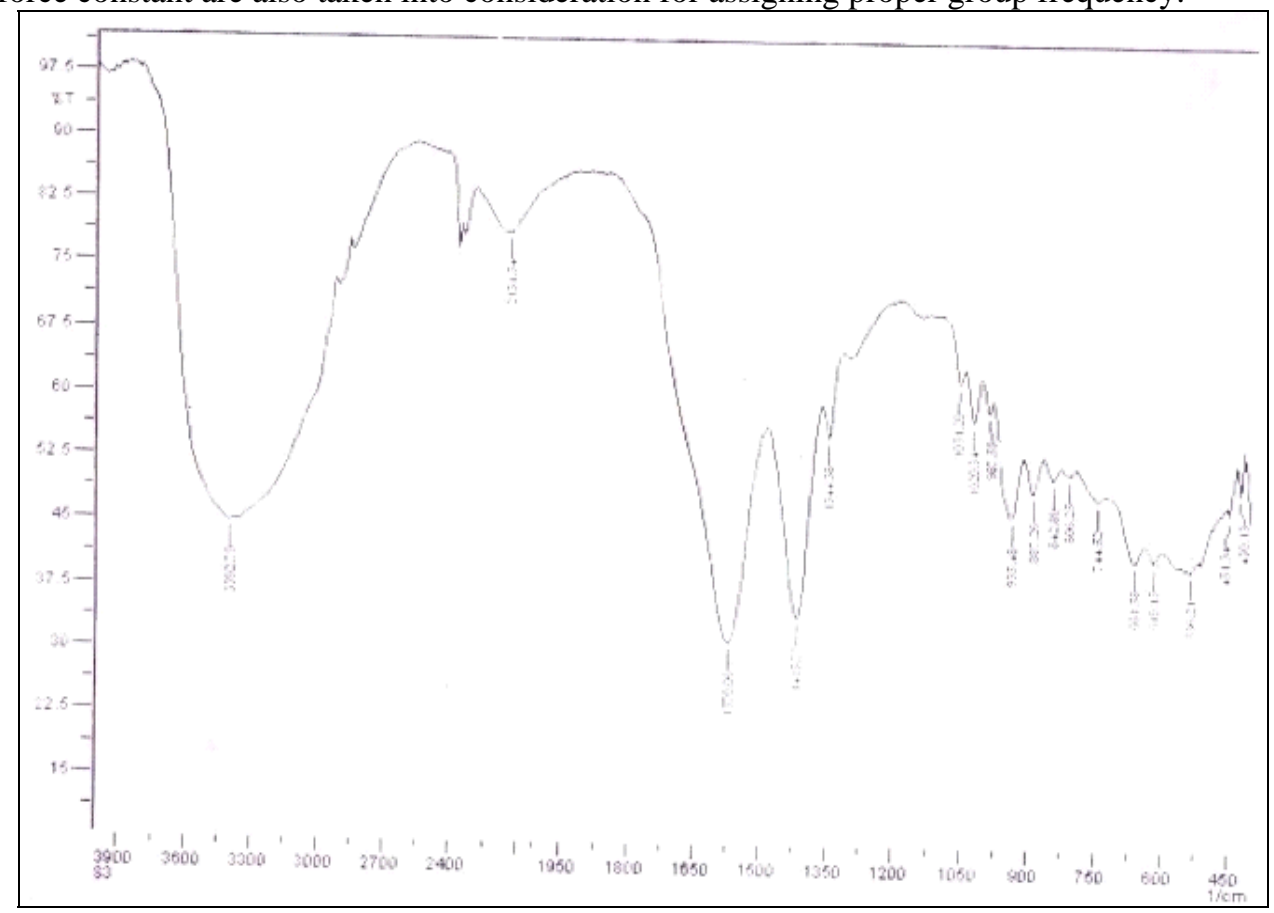

Figure 1. FTIR of Polyvanadate

\section{Thermal studies involving TGA and DTA result}

The TGA curve of the isolated polyvanadate complex (Figure $2 \& 3$ ) indicate multistep of thermal dissociation process in between $25{ }^{\circ} \mathrm{C}$ to $150{ }^{\circ} \mathrm{C}, 150{ }^{\circ} \mathrm{C}$ to $375{ }^{\circ} \mathrm{C}$ and finally from $375^{\circ} \mathrm{C}$ to $600{ }^{\circ} \mathrm{C}$. The formation of triheteropoly complex of vanadium involves metal oxy cations and their structural aspect depends on the specific polyvanadate anion formed.

The formation of product involves intersection of sodium metavanadate anions with $\mathrm{Ni}^{2+}$ and $\mathrm{V}^{5+}$ cations in the acidic medium . The ratio of three metal ion is Co:Ni:V (1:1:6) producing bright brown coloured product with the suggested composition. The product isolated is quiet stable in air and has poor solubility in cold water. However the product is completely soluble in boiling water. 


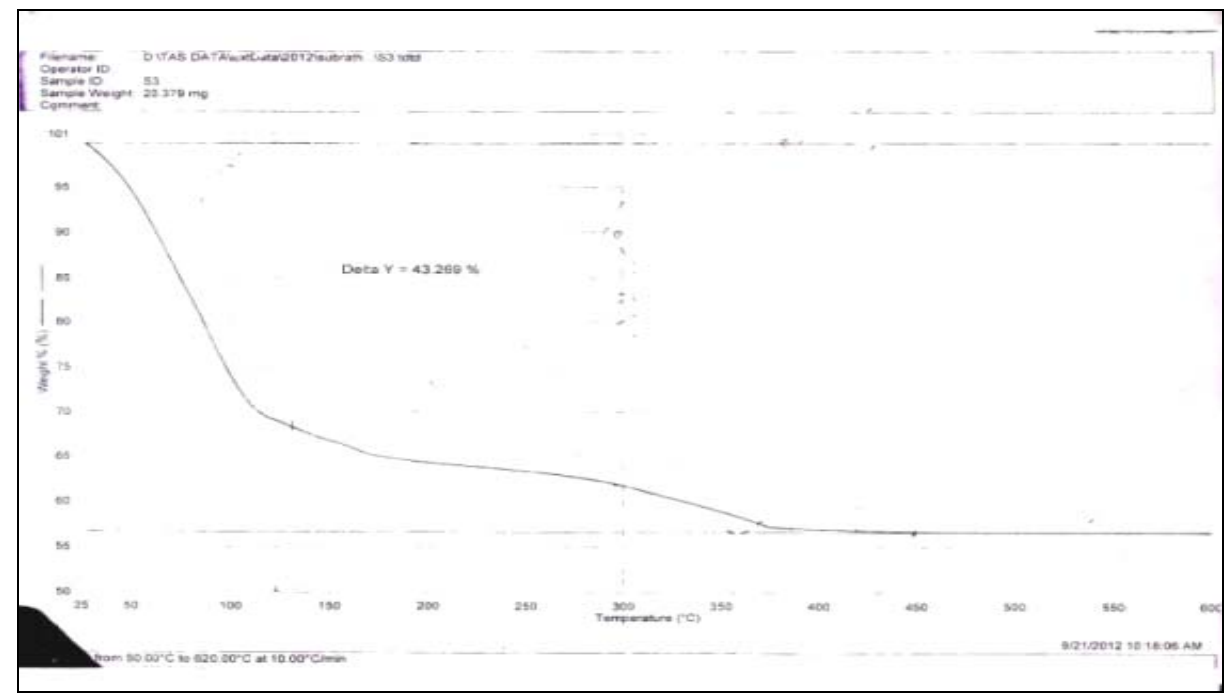

Figure 2. TGA graph of polyvanadate

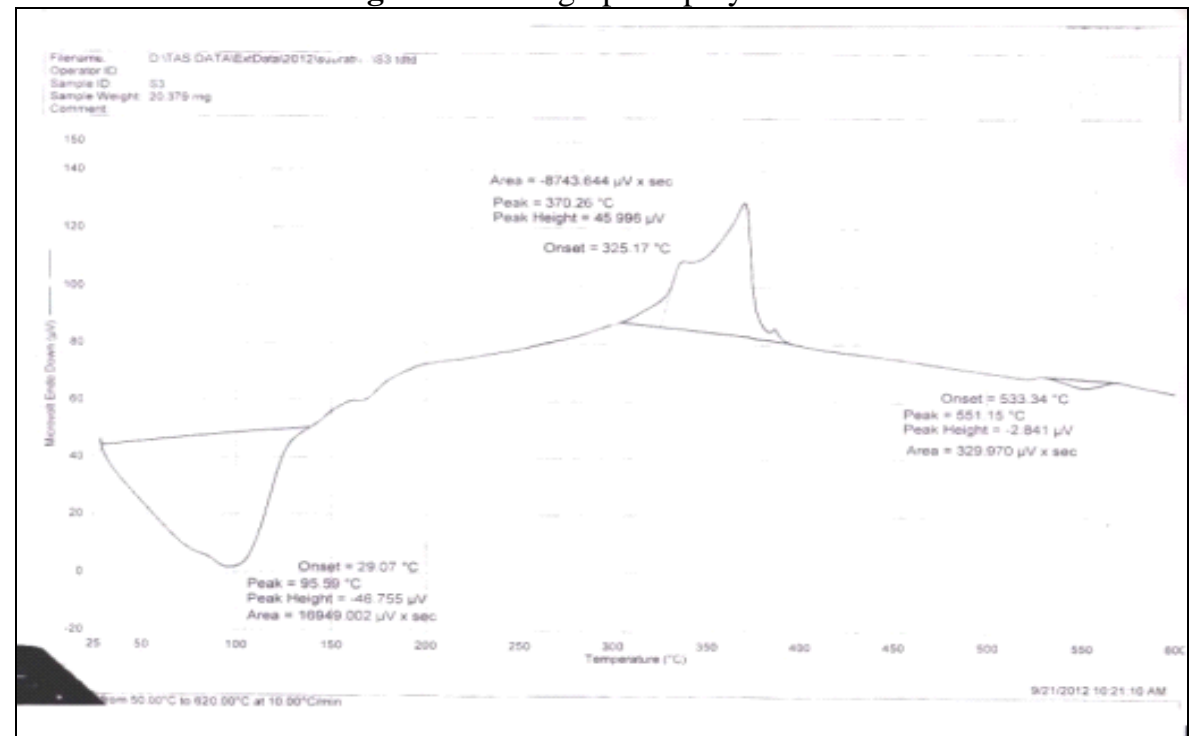

Figure 3. DTA graph of polyvanadate

The aqueous solution of the triheteropoly complex is ionic in nature containing sodium cations. The presence of sodium cation was confirmed by the IR spectral analysis of the sample and also from the flame photometric experiment which form golden yellow flame of sodium. The thermal stability of the complex was studied by TGA and DTA analysis. However the modes of different type of $\mu \mathrm{H}_{2} \mathrm{O}$ group molecules cannot be demarcated clearly. The thermal analysis indicates that the thermolysis of the metal oxides complex proceeds by loosing first the water of crystallization and then subsequently the water of constitution to form oxometallates bridge ${ }^{16}$. Which are important to the structure of heteropoly complex compound. The first thermal decomposition involves of $\mathrm{H}_{2} \mathrm{O}$ molecules. The measure weight loss of the product at $25^{\circ} \mathrm{C}$ to $75^{\circ} \mathrm{C}$ is about $32 \%$. The measure weight 
loss of the product is accompanied by phase transfer as indicated in the DTA graph suggesting exothermic peak maxima at $29.07{ }^{\circ} \mathrm{C}$ temperature having area $16949.002 \mu \mathrm{Vx}$ sec and peak height $-46.755 \mu \mathrm{V}$. In second thermal decomposition involves elimination of $\mathrm{H}_{2} \mathrm{O}$ molecules. The weight loss of the product between $75^{\circ} \mathrm{C}$ to $375{ }^{\circ} \mathrm{C}$ is about $11 \%$. The weight loss of the product is accompanied by phase transfer as indicated in the DTA graph suggesting endothermic peak maxima at $370.26^{\circ} \mathrm{C}$ temperature having area $16949.002 \mu \mathrm{Vx}$ sec and peak height $45.996 \mu \mathrm{V}$. The residue product after $375{ }^{\circ} \mathrm{C}$ up to $600{ }^{\circ} \mathrm{C}$ temperature involve no further weight loss. The composition of the residue product after $375^{\circ} \mathrm{C}$ to $600{ }^{\circ} \mathrm{C}$ temperature may be attributed as $\left[\mathrm{NiCoV}_{6} \mathrm{O}_{18}\right]$.The small exothermic peak maxima is also observed at $533.34{ }^{\circ} \mathrm{C}$ which may be attributed to minor phase transfer of the residue product to settle for long at high temperature.

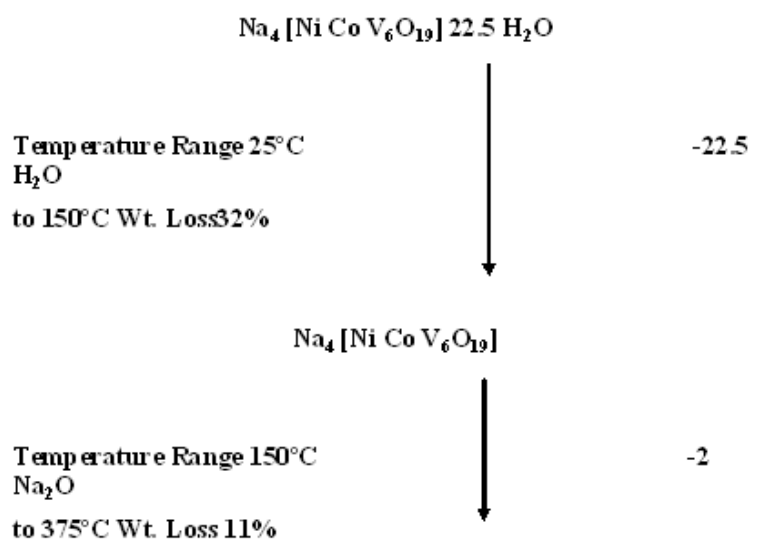

$\left[\mathrm{NiO} \mathrm{CoO} \sigma \mathrm{VO}_{3}\right]$

\section{Acknowledgement}

The authors are thankful to IIT Bombay for TGA and DTA analysis.

\section{References}

1. Topic in Current Chemistry, Spinger-verlag, Berlin, Heidelberg, 1978, 76, 165.

2. Pope M T, Heteropoly and Isopoly oxometalates, Inorganic Chemistry, SpingerVerlag Berlin Heidelberg, 1983.

3. John B Moffat, Metal-Oxygen clusters. The surface and catalytic properties of Heteropoly oxometalates, Kluwer Academic publisher New York, Boston Dordrecht, London, Moscow, 2002, 41.

4. Firouzabadi H and Japari A A, J Iranian Chem Soc., 2005, 2, 85-114; DOI:10.1007/BF03247201

5. Anderson T M, Hardeastle K I, Okum N and Hil C L, Inorg Chem., 2001, 40(25), 6418-6425; DOI:10.1021/ic0105314

(a) Trost B M, Science, 1991, 254, 1471-1477; (b) Referenced in Bolm C, Beckmann

O, Dabard O A G, Angew Chem Int Ed., 1999, 38(7), 907-909;

DOI:10.1002/(SICI)1521-3773(19990401)38:7<907::AID-ANIE907>3.0.CO;2-\#

6. IUPAC System, Nomenclature of Inorganic Chemistry, Butterworth, London, 1959, 73.

7. La Ginestra A and Cerri R, Gazz Chim Ital., 1965, 95, 26.

8. Brukholder E, Golub V, Connor J O and Zubieta J, Inorg Chem., 2003, 42(21), 67296740; DOI:10.1021/ic030169o 
9. Perloff A, Inorg Chem., 1970, 9(10), 2228-2239; DOI:10.1021/ic50092a006

10. Erik's K, Yannoni N F, Agrawal U C, Simons V E and Baker L C W, Acta Cyst., 1960, 13, 1139.

11. Wells A F, Structural Inorganic Chemistry $3^{\text {rd }}$ Edition, Oxford, 1962, 451.

12. West S F and Audrieth L F, J Phys Chem., 1955, 59(10), 1069-1072.

13. Mishra H C, Roy S K and Ojha A N, J Indian Chem Soc., 1978, 54, 307.

14. Alexander G B, J Am Chem Soc., 1954, 76(8), 2094-2096; DOI:10.1021/ja01637a017

15. Vogel A I, A Text Book of Quantitative Inorganic Analysis Including Elementary Instrumental Analysis, ECBS, 1971.

16. Dey K C and Sharma V S, J Indian Chem Soc., 2008, 85, 985-987. 